\title{
As salas de cinema como evidência da reprodução do espaço urbano na região conurbada de Florianópolis/SC
}

\author{
Movie theaters as urban space reproduction evidencies at the \\ Florianópolis/SC conurbed region
}

\author{
Rodrigo Sartori Bogo'
}

\section{RESUMO}

A (re)produção do espaço urbano é, para cientistas que estudam as cidades em suas mais variadas escalas, um processo de significativa importância à pelo menos cinco décadas, considerando o trabalhos seminais de Henri Lefebvre. Problematizar e evidenciar empiricamente a ocorrência deste fenômeno nas metrópoles (e demais cidades) de um país semiperiférico e socioespacialmente desigual como o Brasil é tarefa de pesquisadores da ciência geográfica. A partir disso elaborou-se como objetivo deste trabalho identificar o processo histórico de espacialização das salas de cinema na região conurbada de Florianópolis e analisar quais as relações deste com a reprodução do espaço urbano. Para tal, coletaram-se dados de fontes primárias e secundárias acerca das salas de cinema, as representando espacialmente por via de Sistemas de Informação Geográfica, relacionando-as com as análises da bibliografia especializada. Os resultados demonstraram que as salas de cinema evidenciam claramente a ocorrência do fenômeno supracitado em Florianópolis, somando-se a outros como formação de enclaves fortificados, autosegregação, criação de novos polos de valorização, enclausuramento da vida urbana e fragmentação do tecido sócio-espacial da cidade. Concluiu-se, portanto, que se tratam de consequências da urbanização capitalista manifestando resultados espaciais que são uma amálgama de condições das escalas local, regional, nacional e global.

Palavras-chave: Direito à cidade; Enclaves fortificados; Grande Florianópolis; Reprodução do espaço urbano; Salas de cinema;

\section{ABSTRACT}

The urban space reproduction is, for scientists of urban studies in all scales, a process with great importance for at least five decades, considering the founding works of Henri Lefebvre. To problematize and empirically show the occurrence of this phenomenon at the metropolis (and other cities) of a semiperipheral and spatially unequal as Brazil it's work for geographic science researchers. From that the objective of this research was made, to identify the movie theaters historical process of spatialization at the Florianópolis conurbed region and to analyze what are its relations with the reproduction of the urban space. To do that, data from primary and secondary sources about the movie theaters were collected, then represented spatially through Geographic Information Systems, creating relations between it and others skilled authors analysis. The results show that the movie theaters are a clear evidence of the above-mentioned phenomenon in Florianópolis, together with others like the formations of closed condos, self-segregation, the creation of new high land value spots, the enclosure of urban life and the fragmentation of the urban tissue. Therefore, the conclusions are that these phenomena are consequence of the way that the capitalist urbanization spatially manifests itself, resulting in a spatial mixture between conditions of the local, regional, national and global scales.

Keywords: Closed condos; Greater Florianópolis; Movie theaters; Right to the city; Urban space reproduction; 


\section{INTRODUÇÃO}

A reprodução do espaço urbano é um fenômeno de grande destaque dentre geógrafos de todo o mundo, que estudam a relação entre capital financeiro e imobiliário e sua expansão, horizontal e vertical, por cidades dos países centrais e também dos periféricos. Como ressalta Carlos (2012), baseando-se nos pensamentos de Henri Lefebvre, o espaço não é somente um cenário ou um repositório de formas, mas é por si só também um agente ativo na reprodução das relações sociais e é na cidade em que este efeito aparece mais intensamente. Isso, por si só, já denota a importância desta temática para a ciência geográfica.

Além disso, cabe observar que atualmente, ao final da segunda década do século XXI, o modo de produção capitalista se mantém como hegemônico, funcionando em diferentes escalas e com também variáveis relações entre Estados nacionais e as corporações detentoras de capital e investimento privado. A globalização, essencialmente desigual em seu progressivo espraiamento transescalar (do global ao local) majoritariamente desde os anos 1970, acaba por padronizar as ideias, os modelos e as formas, atingindo diretamente as cidades de todo o mundo. A ideia de cidade-mercado (SÁNCHEZ, 2007) se torna majoritária, observa-se a emergência das políticas competitivas, do planejamento estratégico, num contexto majoritariamente pautado pela ideologia neoliberal. O resultado é um impacto mais visível e desigual nos países periféricos e, como mostra Lacerda (2012), na metrópole latino-americana, fragmentando-a. No entanto, não são só as grandes metrópoles brasileiras que presenciam este fenômeno. Ele se apresenta, reformula e reestrutura cidades e aglomerações urbanas de diferentes dimensões por todo o país, sendo este também o caso de Florianópolis e seu entorno.

A região conurbadai de Florianópolis, visível na Figura 1, é composta atualmente por 4 municípios, sendo eles, além da própria capital: São José, Palhoça e Biguaçu. A estimativa para a população total desta aglomeração é de pouco mais de 970 mil pessoas (IBGE, 2019), considerando-se a totalidade da população dos municípios. Também segundo o IBGE (2007), Florianópolis é, na rede urbana brasileira, uma Capital Regional A, sendo considerada um centro de múltiplas vinculações, subordinada à metrópole de Curitiba. Isso, por si só, já configura uma certa importância no cenário de uma rede urbana integrada nacionalmente, mesmo 
que não se possa fazer comparação alguma com, por exemplo, a metrópole global de São Paulo, foco dos trabalhos de Lacerda (2012) e Caldeira (1997).

Figura 1 - Mapa de localização da região conurbada de Florianópolis

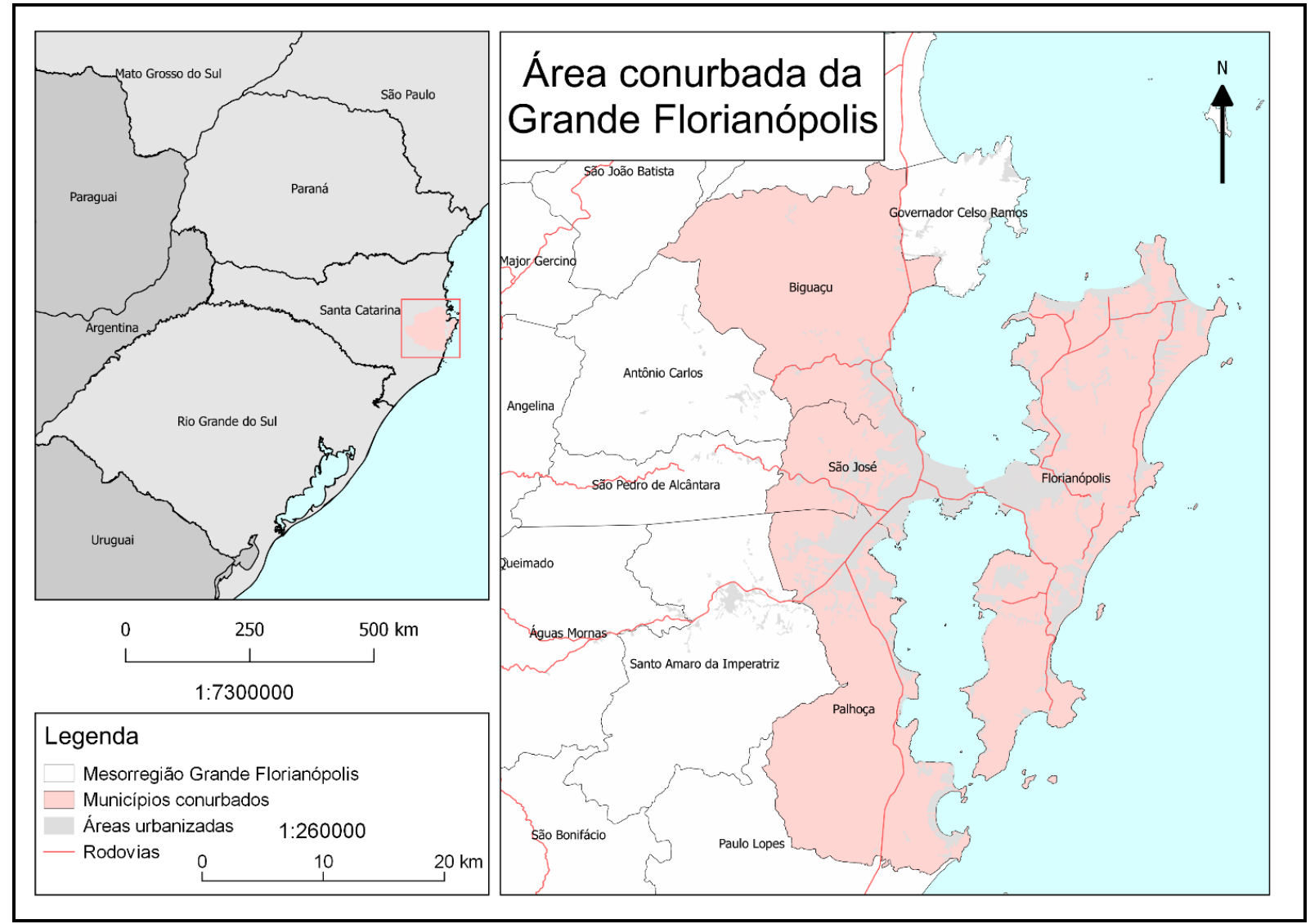

Fonte: IBGE (2015) e DNIT (2015). Elaborado pelo autor;

Tal área conurbada foi composta por processos de segregação urbana e desigualdades sócio-espaciais latentes e que estão historicamente embasados, como demonstram Sugai (2014) e Santos (2009). Nesta pesquisa, especificamente, buscouse mostrar evidências deste processo espacial, com suas particularidades e influências das dinâmicas locais, tendo como objeto as salas de cinema de Florianópolis. Portanto, neste momento introdutório devem ser feitas duas breves explanações: a justificativa da escolha do objeto e a metodologia utilizada para a compilação dos dados, assim como o recorte espacial resultante.

As salas de cinema carregam consigo um forte teor simbólico (MARIA, 2008), envolvendo aspectos acerca de lazer e arte integrados à vida urbana (e que fazem parte do direito à cidade lefebvriano, que será visto adiante), mas são também 
termômetros comerciais e da espacialização do capital. Como discutido a seguir, a arte cinematográfica surgiu já integrada ao modo de produção capitalista, sendo o círculo de cinema comercial internacional um articulador de grandes montantes de capital. A localização de suas salas, portanto, são majoritariamente integradas com práticas espaciais que estão de acordo princípios oriundos do modelo capitalista hegemônico e, como mostram os resultados deste trabalho, sofreram forte influência das alterações do modo de vida impostas pela globalização.

\section{MATERIAIS E MÉTODOS}

Para catalogar e espacializar os dados, utilizou-se como fonte o extenso trabalho realizado por Ramos (2018), de resgate histórico aos cinemas de rua do centro de Florianópolis desde o seu início até a decadência nos anos 1990. Vellozo (2018), em pesquisa de caráter jornalístico, também fornece dados que deram subsídio a este trabalho. Consequentemente, o recorte espacial dos cinemas de rua ficou quase que restrita ao centro da capital, com poucas exceções, mesmo sabendose que a existência de cinemas de rua não era exclusividade desta áreaii.

Partindo das informações e endereços fornecidos nos trabalhos supracitados foi possível levantar pontos que representassem sua localização geográfica, utilizando-se de análise de imagens no recorte descrito, majoritariamente por via do programa Google Earth Pro, caracterizando uma coleta de tipo secundário. Já em relação aos shoppings centers e as salas de cinema que fazem parte destes, a obtenção de informações se deu de forma primária, diretamente em seus sites institucionais, sendo posteriormente espacializados. A tais dados foram vinculados determinados critérios e tratados em software SIG (Sistema de Informações Geográficas), especificamente o QGIS 2.18.19, utilizado também para gerar materiais gráficos, nomeadamente os mapas. Com tais informações do objeto sistematizadas foi essencial levantar, por revisão bibliográfica de tipo primário entre artigos, livros e teses, o arcabouço teórico necessário para consolidar o qualificado debate proposto nesta pesquisa. 
Neste momento, estando claros a motivação, o recorte e a metodologia utilizada, cabe aprofundar-se acerca das salas de cinema em si e sua relação com o espaço urbano, algo a ser realizado na próxima seção deste trabalho. Posteriormente, serão apresentadas e discutidas as bases conceituais da reprodução do espaço urbano, assim como de processos correlatos, como a formação de enclaves fortificados. A partir disso será possível analisar o caso da região conurbada de Florianópolis e sua relação com as salas de cinema, permitindo alcançar a conclusões.

\section{AS SALAS DE CINEMA EM FLORIANÓPOLIS: HISTÓRIA E ESPACIALIDADE}

Inicialmente, cabe fazer uma breve ressalva acerca dos processos em múltiplas escalas que ocorreram (e de certa forma, ainda ocorrem) para que o desenvolvimento do cinema comercial tivesse lugar em Florianópolis e nos demais municípios que, atualmente, compõem a sua região conurbada.

O cinema surgiu por via de um avanço tecnológico, o cinematógrafo, desenvolvido pelos Irmãos Lumiére, na França, na última década do século XIX. O princípio básico trata de uma sequência de fotografias, que projetadas em alta velocidade, acabam por passar a sensação de "movimento" ao espectador, sendo este princípio o utilizado durante toda a "era analógica" do cinema, antes do advento da tecnologia digital (KEMP, 2011).

No entanto, há um aspecto importante deste momento histórico e que veio a influenciar a arte cinematográfica em todo o seu caminho até os momentos atuais: o fato de que a mesma surgiu já sob a lógica capitalistaiii. Isso permitiu uma rápida expansão desta tecnologia pelo mundo (para os padrões da época, naturalmente) e também um crescente fascínio do público para apreciar as imagens em movimento. Soma-se a isso o zeitgeist intelectual do período, atrelado ao ideário do positivismo, do progresso e da modernização presentes durante a Segunda Revolução Industrial. 
O Brasil, neste momento, apresentava uma economia majoritariamente agrícola, industrialização incipiente, uma população que vivia, em sua maioria, no campo, além de baixa integração nacional dentre os mais diversos fluxos que ocorriam em seu território (SANTOS, 2013). No entanto, isso não impediu que a elite intelectual e econômica tivesse um relativo grau de integração com a Europa, e foi tal aspecto que permitiu a rápida chegada do cinematógrafo (e consequentemente, do cinema) ao contexto brasileiro. No início, espalharam-se, especialmente pelas maiores cidades brasileiras os chamados "cinemas itinerantes"iv, em que a aparelhagem era levada de cidade em cidade e eram exibidas sessões esporádicas em parques ou teatros, por exemplo. Foi entre os anos de 1908 e 1913 que, a nível nacional, começaram a se estabelecer as salas de cinema como um espaço comercial fixo (POZZO, 2015).

Em Florianópolis, este processo se deu no mesmo momento histórico, o que evidencia a rápida expansão deste modelo de negócio pelo país, visto a condição periférica da capital catarinense, especialmente naquele período. Como já ressaltado anteriormente na introdução, o trabalho de coleta e apresentação dos dados realizados especialmente por Ramos (2018), bem como a abordagem de Vellozo (2018) e as breves adições de Muller (2010) balizaram a descrição do processo histórico a seguir.

O cinema-mudo, como era em tal período, teve suas primeiras salas de exibição fixas no centro Florianópolis abertas nos anos de 1909 (Cassino) e 1910 (ArtNouveaux, posteriormente outras), respectivamente na Praça XV e no Teatro Álvaro de Carvalho. Logo depois, em 1912 e 1913, foram fundadas mais duas no centro, chamadas Cinema Círculo e Cinema Ideal. Foram mais 6 anos até que surgisse uma nova sala, o Ponto-Chic, que acabou por fechar em 1928 (RAMOS, 2018). O autor também descreve o surgimento de outras salas de cinema ainda no contexto do cinema-mudo (objetivo inicial do trabalho de Ramos), como o Cine Internacional, o Ideal e o Centro Popular (Tabela 1). 
Tabela 1 - Salas de cinema abertas no período do cinema-mudo

\begin{tabular}{c|c|c}
\hline Cinema & Data de fundação & Data de encerramento \\
\hline Cassino & 1909 & $\mathrm{~s} / \mathrm{d}^{\mathrm{v}}$ \\
\hline $\begin{array}{c}\text { Art-Nouveaux } \\
\text { (posteriormente outros) }\end{array}$ & 1910 & 1955 \\
\hline Círculo & 1912 & $\mathrm{~s} / \mathrm{d}$ \\
\hline Ideal & 1913 & $\mathrm{~s} / \mathrm{d}$ \\
\hline Ponto-Chic & 1919 & 1928 \\
\hline Internacional & 1924 & $\mathrm{~s} / \mathrm{d}$ \\
\hline Idealvi & 1930 & $\mathrm{~s} / \mathrm{d}$ \\
\hline $\begin{array}{c}\text { Centro Popular } \\
\text { (posteriormente outros) }\end{array}$ & 1930 & $\mathrm{~s} / \mathrm{d}$ \\
\hline
\end{tabular}

Fonte: Ramos (2018), elaborado pelo autor;

Um aspecto a ser ressaltado e que também é citado por Vellozo (2018), é de como a mídia da época, assim como historiadores e demais estudiosos, fazem correlações entre o surgimento e o posterior aumento das salas de cinema no centro de Florianópolis e o crescente "progresso" que chegava à capital naquele período, representados especialmente pelas obras de saneamento, a expansão do centro e a construção da ponte Hercílio Luz, em 1926.

Existem também relatos acerca de uma suposta "integração" da população por via da arte cinematográfica, acessível às diferentes classes sociais. No entanto, como tratado por Santos (2009) as primeiras décadas do século XX e a expansão urbana do centro tiveram como uma de suas consequências espaciais a periferização dos pobres de forma gradativa para áreas mais insalubres, resultando na ocupação dos morros centrais, especialmente pela população negra. Cabe indagar, visto a falta de evidências para afirmar o contrário, se o fenômeno cultural representado pela arte cinematográfica e pelos seus fixos (as salas de cinema) era suficiente para concretizar a tal "integração de classe". vii

Foi somenteviii em 1931 que chegou à Florianópolis a primeira sala de cinema com acesso à tecnologia do filme sonoro, o Cine Palace, que posteriormente veio a se chamar Cine Central. Como ressalta Vellozo (2018), a ruptura não foi imediata: os outros três cinemas que ainda existiam continuavam a exibir filmes mudos, atualizando-se progressivamente. O que se observa a partir daí, auxiliado pelo 
levantamento de Ramos (2018), é que houve um boom de consolidação das salas de exibição na cidade: vieram o Glória (substituído 3 vezes por outros cinemas) em 1932, e também o Rex (posteriormente Ritz) em 1935, somando-se aos já existentes. Ou seja, ao final dos anos 1930 haviam sete salas de cinema em funcionamento somente no centro de Florianópolis. Cabe ressaltar, conforme o já exposto na introdução, que para a totalidade da região conurbada o número é potencialmente maior, considerando em especial a realidade do centro continental e também de São José no período.

No entanto, essa breve aurora recebeu um baque, resultado da conjuntura nacional: a censura proveniente da Ditadura Varguista e o posterior envolvimento do Brasil na Segunda Guerra Mundial, o que diminuiu o número de salas e manteve somente os empreendedores de maior capital ainda ativos neste meio. Isso também arrefeceu a produção cinematográfica nacional e diminuiu a procura da população por esta arte justamente enquanto ocorria a "Era de Ouro"ix do cinema norteamericano (VELLOZO, 2018). Porém, o autor também trata do ressurgimento da exibição de filmes em larga escala na cidade e que se dá especialmente na transição entre o final dos anos 1940 e o decorrer dos 1950, capitaneado principalmente pelos investimentos da família Daux, tradicionais empreendedores florianopolitanos. Além de adquirir salas de outros empresários, também fundaram o Cine São José, em 1954, consolidando-se como os grandes detentores deste segmento empresarial-artístico em Florianópolis.

Naturalmente, este movimento apresentou também propostas paralelas e alternativas, sendo a mais conhecida delas o cinema Central, fundando em 1959 por Darci Costax, mas que fechou somente um ano depois, devido a forte concorrência das salas maiores e já estabelecidas na cidade. É neste contexto que tais salas de cinema se mantiveram durante anos, havendo um novo empreendido fundado somente em 1975, com o Cine Cecomtur, também no centro de Florianópolis, sendo o último de tal característica (Figura 2). 
Figura 2 - Data de fundação dos cinemas de rua do centro de Florianópolis

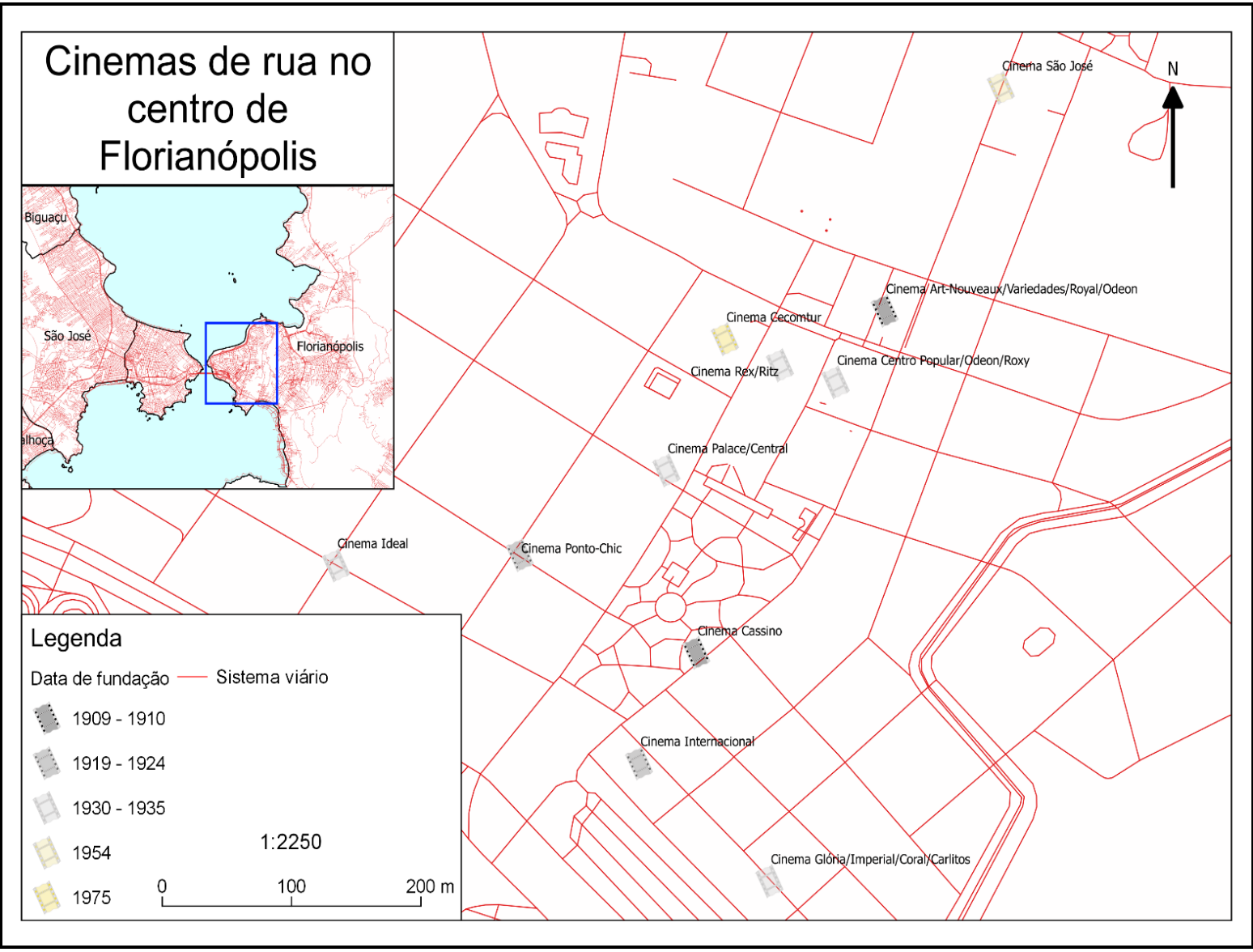

Fonte: Ramos (2018). Elaborado pelo autor;

Neste momento, são perceptíveis uma série de fenômenos transescalares artísticos e espaciais, que não devem aqui ser ignorados. Como descrito e relatado por Pozzo (2015), eram durante os anos 1970 que o Brasil atingiu o seu máximo de salas de cinema em quantidade, assim como uma maior desconcentração espacial destas. Ao mesmo tempo (e até antes, na verdade), a tipologia e os efeitos da reprodução do espaço urbano viriam a se intensificar, primeiramente nos países centrais com o início da espacialização do capital financeiro por via do seu "deslocamento" para a propriedade do solo, como bem descrito por Carlos (2012) e a progressiva alteração das formas das metrópoles, em menor medida, das cidades grandes e médias em contexto nacional, o que é analisado por Lacerda (2012). No entanto, isso será aprofundado na próxima parte.

Além dos fenômenos citados acima, cabe ressaltar que o Brasil passava, em tal momento histórico, por uma ditadura civil-militar, o que alterou significativamente o 
conteúdo dos filmes realizados no país e também a "interpretação" da arte vinda do exterior. A censura era uma constante e este detalhe teve clara influência no que era produzido, reproduzido e consumido em termos de cinema em todo o território nacional, incluindo Florianópolis. Em contrapartida, movimentos artísticos e cinematográficos pipocavam em diversos países, majoritariamente centrais, com destaque para o período de expansão da "contracultura" no cinema hollywoodianoxi.

A partir daí um movimento nacional relatado por Pozzo (2015) se inicia, e sua face em Florianópolis é descrita por Vellozo (2018): a decadência dos cinemas de rua. Como este último autor bem destaca, há uma coalisão de fatores para este fenômeno, sendo eles culturais, econômicos, mas, acima de tudo, socioespaciais. O decorrer dos anos 80 e da "redemocratização" viriam a apresentar as primeiras consequências da globalização, fazendo surgir novas formas espaciais, fluxos mais rápidos e distâncias maiores. A partir da produção e reprodução do capital no solo urbano, migrando em direção à periferia (no caso de Florianópolis, em direção aos bairros litorâneos mais distantes [especialmente no norte da ilha] e na faixa continental, em direção aos municípios conurbados), em consonância com a teoria e as descrições consolidadas por Harvey (2000 apud VALENÇA, 2008).

As novas formas espaciais supracitadas, viriam a se tornar vetor de maior fragmentação do espaço urbano, a partir da consolidação dos chamados enclaves urbanos (CALDEIRA, 1997). Na região conurbada de Florianópolis, dois marcos muito significativos são a construção e fundação de dois shoppings centers: o Shopping Itaguaçu, no município de São Joséxii, em 1982; e o Shopping Beira-Mar, entre as avenidas Mauro Ramos e Beira-Mar Norte, em 1993.

Não só como resultado de fenômenos nacionais e globais que viriam a influenciar o espaço urbano, sua produção e reprodução (do qual será discutido a seguir), mas também é visto a partir desse momento os sintomas do que Pozzo (2015) considera uma "ditadura da tecnologia", num contexto em que qualidade técnica das salas e seu conforto acabam por, progressivamente, se tornarem mais importantes ao espectador do que o ato de assistir um filme em si. Destarte a necessidade de modernização das salas, foram os grandes capitais, nacionais e internacionais, que 
foram responsáveis por este salto tecnológico nas salas de cinema e, importante ressaltar, praticamente os únicos a terem o aporte financeiro para fazê-lo.

O efeito resultante foi, como citado anteriormente, uma progressiva decadência dos cinemas de rua, que conforme descrito por Vellozo (2018) para o caso florianopolitano, baseando-se em relatos de indivíduos que viveram e estudaram o auge destes, pode ser visto como um final "melancólico". Uma correlação evidente a ser observada é entre a data de encerramento destes cinemas de rua consolidados por décadas e o aparecimento dos cinemas do tipo multiplex (POZZO, 2015), já atrelados ao modelo de negócio dos shoppings centers e que acabam por representar uma nova fase nos modos de consumo da população, representando claramente o que Albernaz (2007) chama de enclausuramento da vida urbana. As tabelas 2 e 3 servem para demonstrar a relação entre o surgimento destes dois shoppings e o "fim" do modelo de negócio dos cinemas de rua.

Tabela 2 - Data de fundação dos primeiros shoppings centers da região conurbada de Florianópolis

\begin{tabular}{c|c|c}
\hline Empreendimento & Ano de fundação & Localização \\
\hline Shopping Itaguaçu & 1982 & Município de São José \\
\hline Shopping Beira-Mar & 1993 & Área central de Florianópolis \\
\hline
\end{tabular}

Fonte: Vellozo (2018), elaborado pelo autor;

Tabela 3 - Período de funcionamento dos cinemas de rua sonoros no centro de Florianópolis

\begin{tabular}{c|c|c}
\hline Cinema & Data de Fundação & Data de Encerramento \\
\hline Royal / Odeon & $1910^{\text {xiii }}$ & 1955 \\
\hline Roxy & $1930^{\text {xiv }}$ & 1992 \\
\hline Glória / Imperial / Coral / & 1932 & \\
Carlitos & & 1995 \\
\hline Rex / Ritz & 1935 & 1994 \\
São José & 1954 & 1994 \\
\hline Cecomtur & 1975 & 1994 \\
\hline Scala / Império / Jalisco & 1960 & \\
\hline
\end{tabular}

Fonte: Ramos (2018) e Muller (2010), elaborado pelo autor; 
O principal a ser notado pelo leitor são as datas de encerramento sublinhadas. Estão desta forma para destacar como o surgimento do Shopping Beira-Mar, acompanhado de salas de cinema que representavam o novo modelo de negócio vinculado a novos padrões mundiais (e consequentemente nacionais) de consumo e vivência, foi determinante para findar as atividades dos cinemas de rua da área central, somando-se a eles o caso do Cine Jalisco, no Estreito. Portanto, o triênio 1993-1995 serviu como marca determinante na transformação dos hábitos e do consumo da população da região conurbada de Florianópolis em relação à arte cinematográfica, em acordo com o que vinha ocorrendo nas grandes metrópoles brasileiras, o que é destacado por Pozzo (2015) e pode ser visto na Figura 3.

Figura 3 - Data de encerramento dos cinemas de rua de Florianópolis

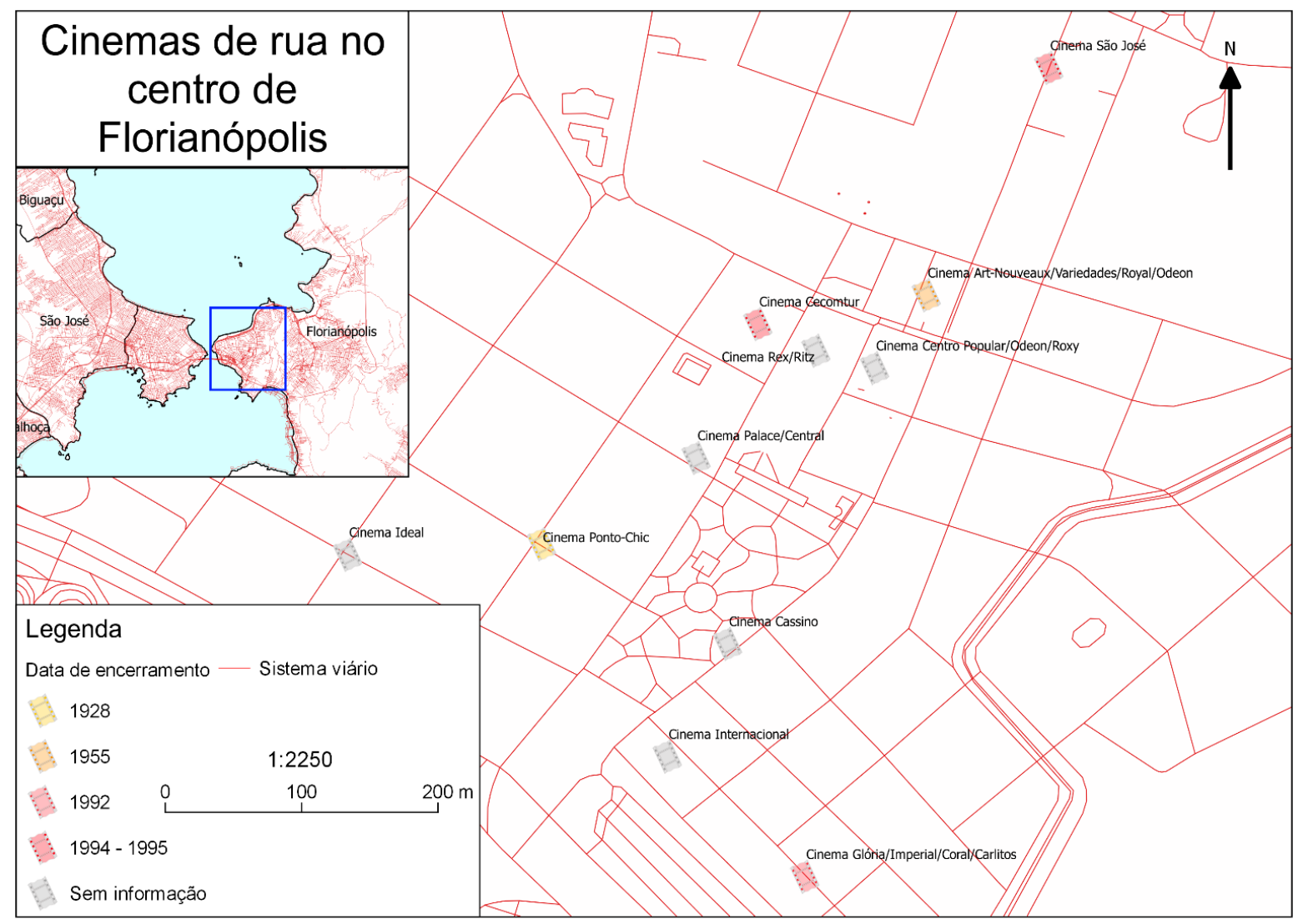

Fonte: Ramos (2018) \& Vellozo (2018); Elaborado pelo autor;

Com o claro gap deixado pelos cinemas de rua, a reestruturação do espaço urbano continuou a se expandir de forma a moldar e também consolidar novos hábitos de consumo de cultura, lazer e serviços, utilizando-se do modelo de 
empresariamento urbano discutido massivamente por Harvey (1996). Foi a partir deste contexto que novas oportunidades de negócio, de expansão de grandes centros empresariais e projetos arquitetônicos de porte significativo apareceram progressivamente na região conurbada de Florianópolis, intensificando o processo de mercantilização da cidade e sua consequente posição como cidade-mercadoria em sua apresentação frente ao globo, conforme as críticas de Sánchez (2007). Ainda que a autora discuta estes termos para o caso metropolitano, acredita-se que o mesmo vale para Florianópolis e seu entorno, visto que o mito da cidade empreendedora, citada pela mesma, é muito cara a este espaço.

Uma consequência deste processo foi o surgimento de novos Shoppings Centers e centros empresariais, resultando num fenômeno que se intensificou a partir da segunda metade da década de 2000, aumentando continuadamente na década de 2010 até o momento de elaboração deste artigo. A Figura 4 deixa este fenômeno evidente em sua forma espacial.

Figura 4 - Data de fundação dos shoppings centers

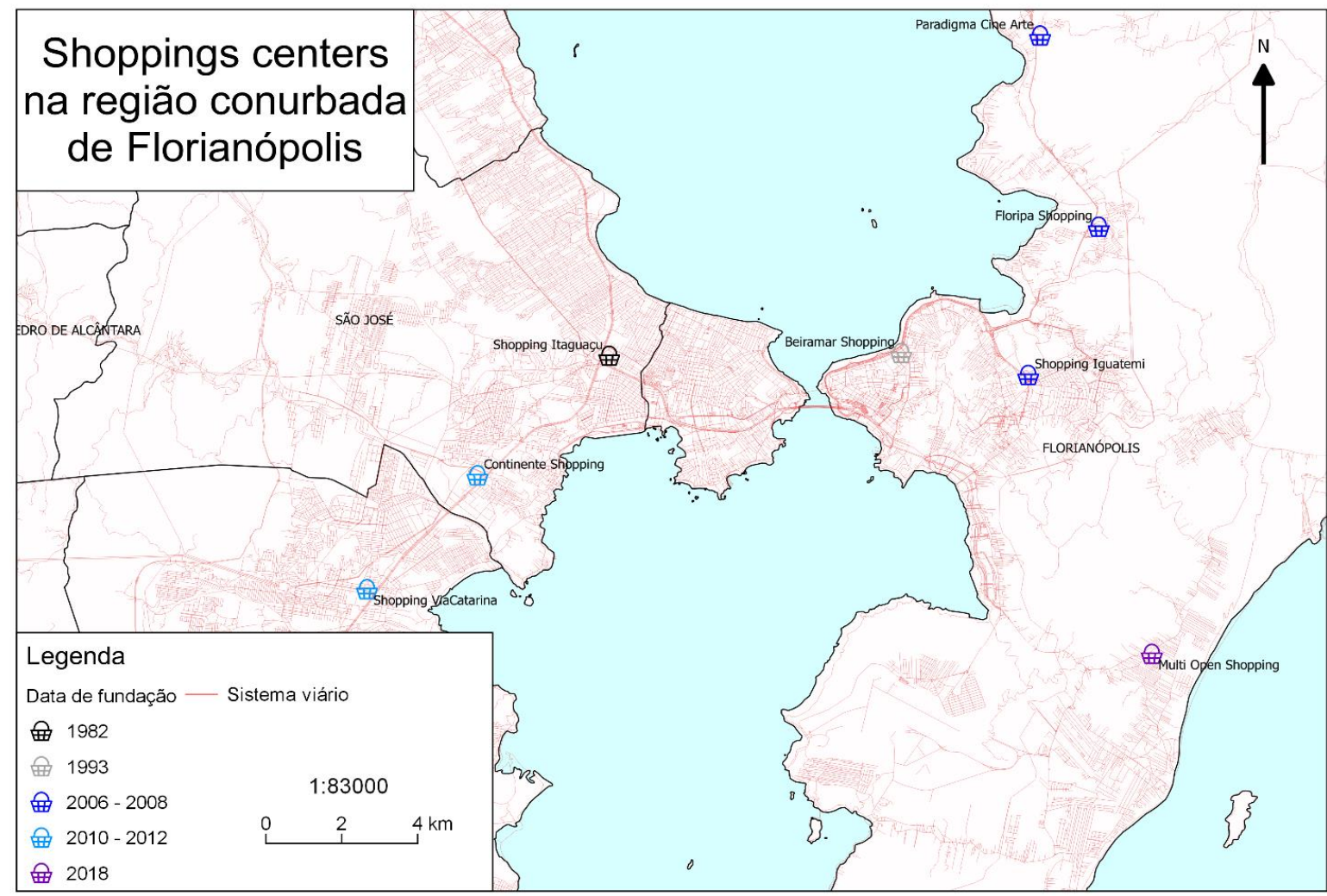

Fonte: Vellozzo (2018), Continente Shopping (2019) e Shopping ViaCatarina (2019); Elaborado pelo autor; 
Um aspecto relevante a ser destacado é a inclusão tanto do Paradigma Cine Arte quanto do novo Multi Open Shopping nesta lista. Ainda que ambos os cinemas destaquem, por via de seus respectivos portais institucionais (PARADIGMA CINE ARTE, 2019; MULTI OPEN SHOPPING, 2019;) que buscam exibir sessões cinemato gráficas do tipo cult e "de arte", nos dois casos estes empreendimentos, ainda que apresentem um modelo de negócio diferenciado em relação ao modelo multiplex dos outros shoppings centers, estão inseridos em centros comerciais e são parte do mesmo fenômeno imobiliário (e consequentemente geográfico) aqui analisado.

Porém, compreender adequadamente este fenômeno e o porquê de ter ocorrido demanda um levantamento teórico mais denso do que as breves citações feitas em momentos oportunos até aqui. Discutir a reprodução do espaço urbano significa tratar de uma das principais temáticas da ciência geográfica em âmbito nacional e internacional nas últimas décadas e o trabalho realizado aqui busca uma primeira aproximação, de forma a balizar as discussões trazidas à tona.

\section{A REPRODUÇÃO DO ESPAÇO URBANO}

A ideia de produção e reprodução do espaço urbano tem sido cara para a ciência geográfica, visto a importância que as cidades apresentam nos estudos em ciências humanas como um todo e também na intensificação contínua dos fenômenos de reestruturação urbana que ocorrem nos países centrais e periféricos durante e após o século XX. O principal autor a tratar especificamente deste tema e dedicar uma parte significativa da consolidação de sua massiva teoria sobre este processo espacial é David Harveyxvi, geógrafo inglês de matriz neomarxista, atualmente professor do departamento de antropologia da City University of New York. Um sintético apanhado sobre a compreensão do mesmo acerca da dinâmica do imobiliário nas áreas urbanas pode ser visto em Valença (2008).

No entanto, como será visto adiante, boa parte dos estudos que tratam da reprodução do capital (em diferentes fases, de variadas formas) no solo urbano tendem a focar nas grandes metrópoles, tanto dos países centrais qua nto da periferia 
capitalista, o que tem sim seu sentido: são nestas grandes aglomerações em que o capital é mais dinâmico, os fluxos são mais intensos, os efeitos causam consequências à um contingente populacional mais significativo e é onde se dá, normalmente, a tomada de decisão. São nas chamadas cidades globais que vão ocorrer os fenômenos urbanos de maior impacto, como o gentrification por exemplo, do qual BidouZachariasen (2006) fez importante apanhado para diferentes cidades em diferentes escalas.

Ora, isso não invalida que se identifiquem evidências, sintomas e quiçá o "pacote completo" do fenômeno da reprodução em aglomerações urbanas de menor escala, como é o caso de Florianópolis. Não se assume aqui que os processos ocorridos neste estudo de caso são os mesmos ou sequer versões "rudimentares" do que acontece em São Paulo ou Nova lorque, mas sim que existem dinâmicas espaciais e suas formas resultantes que são transescalares e se evidenciam em cada lugar conforme as suas próprias características de formação socioespacial. Como reforçado por Souza (2006), cabe aos pesquisadores identificarem as semelhanças e diferenças na ocorrência destes processos, levando sempre em consideração as peculiaridades locais e os diferentes modelos socioespaciais, políticos e econômicos.

Para início desta breve abordagem conceitual, vale retomar os tópicos tratados por Smith (2007). Este argumenta que a reestruturação urbana é um fenômeno que sempre ocorreu nas cidades, assim como a reprodução do capital por via do solo urbano (desde o início do capitalismo neste caso, ressaltando), mas este fenômeno se intensificou massivamente nos países de capitalismo mais desenvolvido e assumiu formas transescalares que antes eram incipientes. Agora, local e global (e claro, seus intermédios) se mostram mais conectados e seus efeitos se materializam no espaço sob uma dinâmica cada vez mais intensa.

Este ponto também é tratado por Sposito (2011), que chama de diferenciação socioespacial tal marca característica da urbanização e que ganhou novos contornos com o capitalismo e ainda mais com a globalização e a financeirização do solo urbano. Segundo a autora "Não há cidades sem divisão social do trabalho, o que pressupõe sempre uma divisão territorial do trabalho. Essa divisão estabelece-se 
diferentemente, no decorrer do longo processo de urbanização." (2011, p. 124). Isso por si só demonstra a importância do espaço como categoria de análise, como reforçado por Carlos (2012, p. 44) "o espaço pode ser definido como um processo que se constitui como produto, condição e meio [grifo da autora] da reprodução da sociedade, iluminando as tendências do mundo atual". Para o contexto urbano não é diferente.

É importante ressaltar também o que Sobarzo (2006), dialogando com Ana Fani Carlos, destaca: que os três níveis de produção do espaço (dominação política, acumulação capitalista e realização da vida humana), de inspiração lefevbriana, se dão também por articulações entre público e privado. As relações capital-Estado resultam em vínculos complexos e que denotam

[...] um panorama em que público e privado se misturam, convivem de forma conflituosa, invadem-se mutuamente, porque, numa sociedade moldada na troca de favor e no clientelismo, não basta a distinção legal para separar ambas as esferas. (SOBARZO, 2006, p. 96)

Assim podemos nos aproximar da síntese de Valença (2008), apoiado na obra de Harvey. Para ele, o que diferencia a cidade capitalista das demais é a transformação dela mesma, a cidade, e seu solo, numa mercadoria, trazendo consigo a noção de propriedade privada. Sendo a cidade uma mercadoria, busca-se o lucro por via dela, num processo que envolve construção, destruição e reconstrução de formas urbanas, assim como valorização, desvalorização e revalorização de novos espaços. Estas noções são determinantes para compreender os movimentos especulativos e de expansão não só das metrópoles, mas também das demais cidades tanto em países centrais quanto periféricos.

Foi Harvey também (2000 apud VALENÇA, 2008) que concebeu o conceito de spatial fix, sendo ele o capital investido em um objeto construído, o que gera impasses e ressignificações na reprodução do espaço urbano. Há, portanto, a constante necessidade de uma destruição criativa e que é resultado direto das necessidades de acumulação do capital pela cidade-mercadoria, sendo ela necessariamente expansionista (normalmente de forma horizontal, as vezes na vertical). Após a Crise do Petróleo de 1973 e a maior abertura econômica, resultante 
também de uma certa erosão do welfare state dos países centrais e também da decadência do pensamento desenvolvimentista, a financeirização do capital se intensificou e começou a utilizar do solo urbano para "materializar" seus ganhos, visto que, como ressalta o próprio autor, investimentos imobiliários envolvem longos prazos e vultuosos investimentos de capital, vindo a receber notáveis aportes financeiros por parte do Estado. A terciarização da economia, em soma, incentivou progressivamente a criação de novos centros empresarias e outras formas de lazer.

Dessa forma, o deslocamento do capital financeiro excedente iniciou o que Harvey chama de "acumulação por espoliação", em que as expansões geográficas mais intensas e as novas regionalizações impostas pela globalização se tornam mais significativas nas cidades, em diferentes contextos. Estando o capitalismo em constante transformaçãoxvii, a frase proferida pelo autor a quase 20 anos se mantém ainda atual

[...] a acumulação de capital foi sempre um evento geográfico. Sem as possibilidades inerentes à expansão geográfica, à reorganização espacial e ao desenvolvimento geográfico desigual, o capitalismo teria, há muito, deixado de funcionar como um sistema político-econômico. (HARVEY, 2000, p. 23 apud VALENÇA, 2008, p. 248)

Somam-se a estas acepções as ideias de Carlos (2012), que avança em alguns conceitos e tópicos para o debate. Para ela, aspectos como a "raridade do espaço" e a "produção da cidade como negócio" são fatores determinantes para que o capital financeiro continue a se concretizar por via da cidade. Apesar do seu enfoque nas metrópoles, estes fenômenos podem ser vistos também em aglomerações menores. Inspirando-se em David Harvey e Neil Smith, a autora fundamenta como a busca por revalorização de centralidades e a necessidade da criação de novas força o solo urbano a perder sua "fixidez", para que possa ser vetor de investimentos e passível de retorno para os lucros.

Outros fatores a serem identificados são características determinantes da atual reprodução do espaço urbano na metrópole (ressalta-se novamente: mas não somente nela), sendo elas, resumidamente: desconcentração produtiva e centralização das decisões; terciarização da economia; consolidação de fundos de investimento 
imobiliário; reforço das relações Estado-espaço; centralização do capital financeiro; dependência da escala local em relação a global conforme as estratégias de reprodução do espaço urbano (CARLOS, 2012).

Todos os fatores citados aqui acabam por ter consequências no espaço urbano, sendo ainda mais abruptas em um país (semi)periférico (SOUZA, 2006) como o Brasil, que queimou etapas, apresenta intensas macrocefalias urbanas e um processo de urbanização, especialmente de suas metrópoles, que pode ser considerado no mínimo intenso, como relatado por Santos (2013). Como resultado, observam-se nas cidades brasileiras (de diferentes formas e intensidades) aspectos de integração e fragmentação, como coloca Lacerda (2012). Para o caso de Florianópolis e sua região conurbada, veremos como a reprodução do espaço urbano gerou diferentes formas de fragmentação, intensificou enclaves urbanos e modificou vivências (o habitar). Como evidência, as salas de cinema, discutidas largamente até aqui.

\section{O CASO DE FLORIANÓPOLIS: SALAS DE CINEMA COMO EVIDÊNCIA DE ENCLAVES E FRAGMENTAÇÃO URBANA}

Florianópolis e sua região conurbada apresenta suas próprias particularidades geográficas em relação aos processos nacionais e globais de reprodução do espaço urbano, em consonância com o alerta proferido por Souza (2006), de que as dinâmicas irão sim apresentar semelhanças dentre as cidades de um mundo globalizado, mas cada qual com suas peculiaridades, que devem ser compreendidas.

Como já citado anteriormente, a posição da capital catarinense e de seu entorno na rede urbana nacional é qualificada como a de uma Capital Regional $A$ (IBGE, 2007), o que por si só a diferencia das grandes metrópoles nacionais (e até globais, como é o caso de São Paulo) ${ }^{\text {xiii. }}$. Algumas consequências são que os processos imobiliários, a aplicação do capital financeiro no solo urbano e o espaço construído resultantes são diferentes do que observados nos centros mais dinâmicos do contexto nacional e também global. O fenômeno de gentrification (BIDOU- 
ZACHARIASEN, 2006; SMITH, 2007), que demanda processos de reestruturação e revalorização urbana em escalas relevantes nas áreas centrais, por exemplo, não teve papel significativo no contexto florianopolitano.

Ainda que o centro da cidade tenha passado por alterações em suas funções e significados dados por parte da população (e também dos promotores imobiliários), como fica evidente, em certo grau, pelo deslocamento espacial dos cinemas para os shoppings centers, nunca houve uma grande alteração nos valores dos imóveis ou na forma de ocupação da área central como um todo. Em acordo com a teorização dada por Harvey (2000 apud VALENÇA, 2008), o capital imobiliário local, atrelado com tendências e fundos de investimento nacionais e globais, utilizou-se da constante expansão geográfica em termos horizontais para valorizar economicamente novos espaços e formar novas centralidades, especialmente nos municípios de Palhoça e São José. Ainda que o aspecto da raridade do espaço (CARLOS, 2012) e da valorização do centro se mantenham presentes, foi este espraiamento constante em direção à centralidades mais distantes e a criação de reservas de valor imobiliário entre tais fixos que caracterizam a constante urbanização da llha de Santa Catarina e do continente próximo, formando diferentes níveis de integração, fragmentação, desigualdade sócio-espacial e segregação ao longo da região conurbada, processo este detalhado espaço-temporalmente por Sugai (2014).

O trabalho da autora supracitada, assim como o de Vera (2018), demonstram a importância que o capital imobiliário tem na reprodução do espaço urbano na fronteira (SMITH, 2007) da conurbação em torno de Florianópolis. Neste trabalho, observa-se por via das salas de cinema que o lazer, o comércio e os serviços acabaram por seguir o mesmo caminho, estando representados pelos shoppings centers. A figura 5, ao comparar a distribuição das salas de cinema na região, deixa clara esta desconcentração em direção às "bordas", distantes da área central. 
Figura 5 - Localização dos atuais shoppings e dos findados cinemas de rua

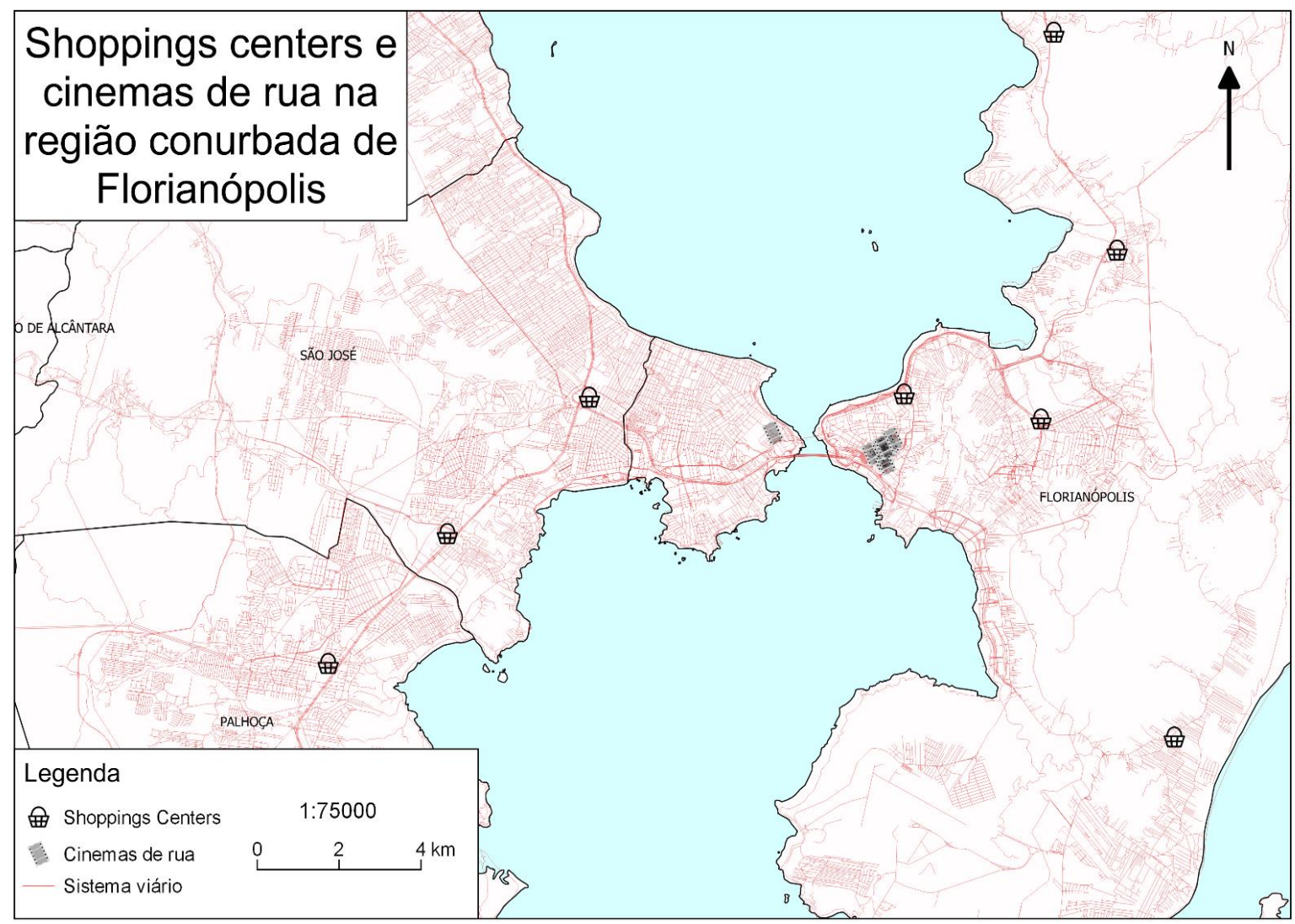

Fonte: Ramos (2018) e Vellozzo (2018). Elaborado pelo autor;

Olhar o mapa acima nos possibilita algumas interpretações, que serão destrinchadas a seguir. Primeiramente, fica perceptível uma maior desconcentração dessa atividade artística e de lazer: o que antes estava resumido ao centro da cidade (ou ao Estreito, no caso do cinema Jalisco) se expandiu para outros bairros e até municípios. O que pode parecer uma vantagem, considerando-se que a população de regiões mais distantes precisa se deslocar menos para ter acesso a salas de cinema (e consequentemente outras formas de lazer, visto o modelo dos shoppings centers) é, na verdade, só a primeira camada de toda a problemática.

A horizontalização do espaço construído, expressa graficamente acima pela migração das salas de cinema para regiões mais distantes do centro "histórico" de Florianópolis é, por si só, uma evidência clara da reprodução do espaço urbano como descrita em Harvey (2000 apud VALENÇA, 2008). Áreas antes desvalorizadas, à margem do centro, com suas dinâmicas particulares, recebem estruturas imensas e 
que estão em consonância com os princípios capitalistas trabalhados à escala global, que buscam o modelo de cidade-mercado (SÁNCHEZ, 2007). Tais áreas são valorizadas (ou revalorizadas), ressignificadas e se tornam polos geradores de fluxo, um novo fixo na cidade, que carrega consigo uma carga simbólica que vai muito além do que antes representavam os cinemas de rua.

A partir disso é necessário discutir conceitualmente a questão da expansão dos shoppings centers e dos centros empresarias como repositórios de lazer e serviços na cidade e quais os seus efeitos em Florianópolis, utilizando-se dos autores que tratam da problemática em diferentes realidades. Os shoppings centers e os centros empresariais fechados, locais que atualmente abrigam a totalidade das salas de cinema do circuito comercial na região conurbada de Florianópolis, são alguns dos principais representantes, em termos de espaço construído, do que Caldeira (1997) intitulou de enclaves urbanos. A autora, que aprofundou seus estudos nos casos de Los Angeles e São Paulo, também cita outras formas que são igualmente importantes para compreender o caso de Florianópolis, como os condomínios fechados (principais representantes do conceito de autosegregação, antagônica à ideia de segregação imposta), enfoque primordial da mesma.

Concorda-se aqui que o "poder de segregação" fortalecido pelos condomínios é significativo no caso florianopolitano e em seu entorno, seja nos conjuntos habitacionais murados do Minha Casa Minha Vida na fronteira metropolitana (VERA, 2018), seja nos condomínios de luxo em bairros como Cacupé ou Saco Grande, na Ilha de Santa Catarina. Porém, como a própria Caldeira (1997) ressalta, outro aspecto importante dos enclaves fortificados é justamente a bandeira do status que carregam, assim como o progressivo distanciamento da vida pública. Os shoppings centers são, quiçá, o maior exemplo da união destes dois fatores: uma desconsideração pelo que representa a vida pública e o status do consumo e do lazer em um ambiente "voltado à si mesmo", como afirma a autora. A expansão, relativamente recente, destas morfologias espaciais na grande Florianópolis representa a priorização da cidademercado em relação à cidade-direito (SANTOS JÚNIOR, 2014) e uma progressiva deterioração da ideia de espaço-público que cria, como consequência, os espaços 
públicos em negativo (ALBERNAZ, 2007). Em resumo, o impacto causado pela proliferação destes espaços privados é descrito por Caldeira (1997), esclarecendo que

Os enclaves privados e a segregação que eles produzem negam muitos dos elementos básicos que constituem a experiência moderna da vida pública: a primazia das ruas e sua abertura; a circulação livre de multidões e veículos; os encontros impessoais e anônimos entre pedestres; o lazer e os encontros públicos em ruas e praças; e, sobretudo, a presença de pessoas de diferentes origens sociais circulando e observando os que passam, olhando as vitrines, fazendo compras, frequentando cafés ou bares, tomando parte em manifestações políticas ou usando os espaços que foram durante muito tempo desenhados especialmente para o entretenimento das massas (passeios públicos, parques, estádios, pavilhões de exposições). (CALDEIRA, 1997, p. 164)

A citação acima e as demais observações realizadas no decorrer deste trabalho acabam se direcionando para o mesmo caminho: o de perceber como a reprodução do espaço urbano, sob a lógica da capitalização do seu solo, no cenário de um país semi-periférico, tende a gerar cada vez mais fragmentação urbana, não sendo necessário o contexto de uma metrópole para que este fenômeno seja significativo e impactante para a população local e seus modos de vida. Aqui, isso se representa por via da relação espaço-temporal entre os cinemas de rua e seus "predecessores", os shoppings centers.

Ainda que Lacerda (2012) paute que a cidade (e especialmente a metrópole) latino-americana deva ser pensada e estudada por seus graus de integraçãoxix e não de segregação, os recortes e rupturas causados por shoppings centers e centros de negócios (que poderiam ser chamados de enclaves fortificados comerciais, adaptando a linguagem) não são unicamente arquitetônicos e físicos, mas também simbólicos, alterando diretamente a identidade com o lugar. Assume-se aqui que a reprodução horizontal do espaço urbano, por via do capital de alto volume, gerando tais formas espaciais, tende a intensificar o processo que Souza (2006) intitula como a fragmentação do tecido sociopolítico-espacial da cidade.

Portanto, essa fragmentação e sua segregação resultante estão diretamente atreladas com a ideia de cidade-mercadoria, em que "Ao lado da exclusão socioespacial, encontra-se a conversão da cidadania ao consumo; ou seja, a criação do indivíduo-consumidor, do cliente passivo de conteúdos materiais e simbólicos, 
alienado de sua comunidade política." (PILATI \& GRASSI, 2018, p. 35). E é esta cidade que está em desacordo com a cidade-direito, conceituada por Santos Júnior (2014), embasando-se no filósofo francês Henri Lefebvre, que elaborou a ideia de direito à cidade, em conjunto com as reinterpretações de David Harvey.

Harvey (2012), ao debruçar-se sobre o assunto, conclui que dentre os caminhos possíveis, o futuro das cidades depende da compreensão mais coletiva das mesmas, de forma que o direito à propriedade privada deixe de se sobressair em relação a os outros. O direito à cidade, difuso e coletivo, que deveria ser vetor de mudança, é perdido quando somente o capital toma as rédeas da reprodução do espaço urbano, elitizando-o e fragmentando-o. Para o autor, a participação popular é o caminho para que as cidades se tornem ambientes não unicamente dependentes do mercado, mas sim espaços de convivência, encontros, desencontros e que atinjam patamares mais elevados de qualidade de vida. O mesmo coloca que

\begin{abstract}
Um passo na direção de unificar essas lutas é adotar o direito à cidade tanto como lema operacional quanto ideal político, justamente porque ele enfoca a questão de quem comanda a conexão necessária entre a urbanização e a utilização do produto excedente. A democratização deste direito e a construção de um amplo movimento social para fortalecer seu desígnio é imperativo, se os despossuídos pretendem tomar para si o controle que, há muito, Ihes tem sido negado, assim como se pretendem instituir novos modos de urbanização. Lefebvre estava certo ao insistir que a revolução tem de ser urbana, no sentido mais amplo deste termo, ou nada mais. (HARVEY, 2012, pg. 88)
\end{abstract}

À guisa de conclusão, ainda há muito o que se avançar no Brasil e em Florianópolis ${ }^{\mathrm{xx}}$ no que diz respeito a práticas participativas e a democratização da cidade, algo extensamente discutido por Souza (2006) e Pereira (2015). São necessárias condições institucionais favoráveis e bem elaboradas, fugindo de possíveis cooptações ou corporativismos, para que planejamento e gestão efetivamente participativos (não meramente consultivos) sejam a norma em nossas cidades. Este deve ser um dos nortes acerca dos debates em geografia e planejamento urbano, para que, em um contexto de efetiva integração de uma cidade-direito, não tenhamos salas de cinema exclusivamente em shoppings centers. 


\section{REFERÊNCIAS}

ALBERNAZ, Paula. Reflexões sobre o espaço público atual. In: LIMA, Evelyn Eurquim Werneck; MALEQUE, Miria Roseira. 7 Letras: Conceitos e leituras. Rio de Janeiro: 7 Letras, 2007. p. 42-57.

BIDOU-ZACHARIASEN, Catherine. Introdução. In: BIDOU-ZACHARIASEN, Catherine. De Volta à Cidade: Dos processos de gentrificação às políticas de "revitalização" dos centros urbanos. São Paulo: Annablume, 2006. Cap. 1. p. 21-57.

BISKIND, Peter. Como a geração sexo-drogas-e-rock'n'roll salvou Hollywood: Easy Riders, Raging Bulls. Rio de Janeiro: Intrínseca, 2009. 504 p.

CALDEIRA, Teresa Pires do Rio. Enclaves fortificados: a nova segregação urbana. Novos Estudos, São Paulo, n. 47, p.155-176, mar. 1997.

CARLOS, Ana Fani Alessandri. A produção da metrópole: o novo sentido do solo urbano na acumulação do capital. In: RIBEIRO, A.C.T.; LIMONAD, E.; GUSMÃO, P.P. (Org.). Desafios ao Planejamento: produção da metrópole e questões ambientais. Rio de Janeiro: Letra Capital, 2012. p. 43-56.

CONTINENTE SHOPPING. Continente Shopping: Informações. 2019. Disponível em: <http://www.continenteshopping.com.br/o-shopping>. Acesso em: 16 mar. 2019.

Departamento Nacional de Infraestrutura de Transportes (DNIT). Shapefiles. 2015. Disponível em: <http://www.dnit.gov.br/mapas-multimodais/shapefiles>. Acesso em: 16 mar. 2019.

HARVEY, David. Do gerenciamento ao empresariamento: a transformação da administração urbana no capitalismo tardio. Espaço e Debates, nº 39, p. 48-64, 1996.

HARVEY, David. O direito à cidade. Lutas Sociais, São Paulo, n. 29, p.73-89, dez. 2012.

Instituto Brasileiro de Geografia e Estatística (IBGE). Áreas Urbanizadas. 2015. Disponível em: $\quad$ <https://www.ibge.gov.br/geociencias-novoportal/organizacao-doterritorio/tipologias-do-territorio/15789-areas-urbanizadas.html?=\&t=downloads $>$. Acesso em: 16 mar. 2019.

Instituto Brasileiro de Geografia e Estatística (IBGE). Portal Cidades. 2019. Disponível em: <https://cidades.ibge.gov.br/>. Acesso em: 16 mar. 2019.

Instituto Brasileiro de Geografia e Estatística (IBGE). Região de Influência das Cidades. Rio de Janeiro: $\quad$ IBGE, 2007. $201 \quad$ p. Disponível em: <https://ww2.ibge.gov.br/home/geociencias/geografia/regic.shtm?c=7>. Acesso em: 16 mar. 2019.

KEMP, Philip (Ed.). Tudo sobre cinema. Rio de Janeiro: Sextante, 2011. 576 p. 
LACERDA, Norma. Fragmentação e integração: movimentos de (re)estruturação espacial das metrópoles brasileiras. In: RIBEIRO, A.C.T.; LIMONAD, E.; GUSMÃO, P.P. (Org.). Desafios ao Planejamento: produção da metrópole e questões ambientais. Rio de Janeiro: Letra Capital, 2012. p. 21-42.

MARIA, Adriana. Paradiso Perdido: A história dos cinemas de rua é esquecida com a modernidade. Diário Catarinense. Florianópolis, 26 set. 2008. Disponível em: <http://www.overmundo.com.br/overblog/paradiso-perdido>. Acesso em: 16 mar. 2018.

MULLER, Jaime. Cinemas de rua de Florianópolis: Bons tempos. 2010. Disponível em: <http://floripendio.blogspot.com/2010/06/cinemas-de-rua-de-florianopolis.html>. Acesso em: 16 mar. 2019.

MULTI OPEN SHOPPING. Multi Open Shopping. 2019. Disponível em: <https://www.multiopenshopping.com.br/>. Acesso em: 16 mar. 2019.

PARADIGMA CINE ARTE. O Espaço. 2019. Disponível em: <http://paradigmacinearte.com.br/o-espaco/>. Acesso em: 16 mar. 2019.

PEREIRA, Elson Manoel (Org.). A Alegoria da Participação: Planos Diretores Participativos Pós-Estatuto da Cidade. Florianópolis: Insular, 2015. 256 p.

PERES, Arlis Buhl et al. Reconstruindo paisagens: desafio socioespaciais para a Grande Florianópolis. Florianópolis: Editora UFSC, 2013. 405 p.

PILATI, José Isaac; GRASSI, Karine. A produção do espaço urbano brasileiro e a mercantilização da cidade. In: CARVALHO, Claudio Oliveira de; GRASSI, Karine; GRAZIANO SOBRINHO, Sérgio

Francisco Carlos (Org.). Vidas urbanas e a vida nas cidades: regramentos urbanos, ambientais, seletividade e violências. Caxias do Sul: Educs, 2018. Cap. 2. p. 22-40.

POZZO, Renata Rogowski. Uma geografia do cinema brasileiro: bloqueios internacionais, contradições internas. 2015. 230 f. Tese (Doutorado) - Curso de Geografia, Departamento de Geociências, Universidade Federal de Santa Catarina, Florianópolis, 2015. Disponível em: <https://repositorio.ufsc.br/handle/123456789/158804>. Acesso em: 16 mar. 2018.

RAMOS, Átila Alcides. Cinemas (de rua) de Floripa: A história dos cinemas de rua de Florianópolis (mudos e sonoros) desde 1900. Florianópolis: 2018. 120 p.

ROSS, Jurandyr. Geografia do Brasil. $5^{a}$ ed. São Paulo: Editora da Universidade de São Paulo, 2005.

SÁNCHEZ, Fernanda. Cultura e renovação urbana: a cidade-mercadoria no espaço global. In: LIMA, Evelyn Eurquim Werneck; MALEQUE, Miria Roseira (Org.). Espaço e cidade: Conceitos e leituras. $2^{a}$ ed. Rio de Janeiro: 7 Letras, 2007. p. 24-41. 
SANTOS, André Luiz. Do mar ao morro. 2009. 657 f. Tese (Doutorado) - Curso de Geografia, Departamento de Geociêncas, Universidade Federal de Santa Catarina, Florianópolis, 2009. Disponível em: <http://labcs.ufsc.br/files/2011/12/Tese-03-PGCN0383T.pdf>. Acesso em: 16 mar. 2018.

SANTOS, Milton. A Urbanização Brasileira. 5. ed. São Paulo: Edusp, 2013. 174 p.

SANTOS JUNIOR, Orlando Alves dos. Urban common space, heterotopia and the right to the city: Reflections on the ideas of Henri Lefebvre and David Harvey. Urbe - Revista Brasileira de Gestão Urbana, [s.I.], v. 6, n. 541, p.146-157, ago. 2014.

SHOPPING VIACATARINA. Shopping ViaCatarina: O nosso shopping. 2019. Disponível em: <http://www.viacatarina.com.br/institucional>. Acesso em: 16 mar. 2019.

SMITH, Neil. Gentrificação, a fronteira e a reestruturação do espaço urbano. GeoUSP Espaço e Tempo. São Paulo, n 21, p. 15-31, 2007.

SOBARZO, Oscar. A produção do espaço público: da dominação à apropriação. GeoUSP Espaço e Tempo. São Paulo, no 19, p. 93-111, 2006.

SOUZA, Marcelo Lopes de. A Prisa e a Ágora: Reflexões em torno da democratização do planejamento e da gestão das cidades. Rio de Janeiro: Bertrand Brasil, 2006. 632 p.

SPOSITO, Maria Encarnação Beltrão. A produção do espaço urbano: escalas, diferenças e desigualdades socioespaciais. In: CARLOS, Ana Fani Alessandri; SOUZA, Marcelo Lopes de;

SPOSITO, Maria Encarnação Beltrão (Org.). A produção do espaço urbano: Agentes e processos, escalas e desafios. São Paulo: Contexto, 2011. p. 123-145.

SUGAI, Maria Inês. Segregação silenciosa: Investimentos Públicos e Dinâmica Socioespacial na Área Conurbada de Florianópolis. Florianópolis: Ufsc, 2014. 200 p.

VALENÇA, Márcio Moraes. Ensaio sobre a dinâmica do imobiliário em Harvey. In: VALENÇA, Márcio Moraes (Ed.). Cidade [i]legal. Rio de Janeiro: Mauad X, 2008. p. 242-249.

VELLOZO, Giovanni. Cinemas manezinhos: uma história. Tu Dix?!. Florianópolis, 20 jun. 2018. Disponível em: <https://medium.com/tudix/cinemas-manezinhos-uma-história8d7b6cac9ec0>. Acesso em: 16 mar. 2019.

VERA, Margaux Hildebrandt. As dinâmicas de metropolização e a atuação dos agentes produtores do espaço urbano na área conurbada de Florianópolis. 2018. 330 f. Tese (Doutorado) - Curso de Geografia, Departamento de Geociências, Universidade Federal de Santa Catarina, Florianópolis, 2018. Disponível em: <https://repositorio.ufsc.br/handle/123456789/191054>. Acesso em: 16 mar. 2019.

WHITELEY, Chris. Hollywood's Golden Age: 30 Years of Brilliance. 2018. Disponível em: <http://www.hollywoodsgoldenage.com/>. Acesso em: 16 mar. 2019. 


\section{NOTAS DE FIM}

i Conforme descrito por Ross (2005), trata-se de uma situação em que os limites urbanos de duas ou mais cidades acabam se "fundindo" e se sobrepõem em relação aos limites administrativos dos municípios.

ii Em conversa informal com Átila Ramos, autor da publicação base para a coleta de dados, o mesmo afirmou ter conhecimento sobre a existência de cinemas de rua no município de São José durante o século XX, estes também estudados por Gilberto Gerlach. No entanto, o autor do presente trabalho não conseguiu coletar estas informações e desconhece também se existiram cinemas do tipo nos municípios de Palhoça e Biguaçu.

iii Kemp (2011) cita que este é um dos principais fatores para que, dentro do debate artístico, haja uma contestação acerca do status de "Sétima Arte" do cinema. Dentre outros argumentos (além da facilidade de reprodução, excessiva massificação, necessidade de "avançado" aparato tecnológico, etc), o fato de música, dança, pintura, escultura, literatura e teatro não terem surgido no modo de produção capitalista (e nem a "seu dispor") balizam esta polêmica. O presente autor, no entanto, não concorda com tal abordagem e irá prosseguir com a forma "padrão", mantendo a alcunha de arte cinematográfica.

iv A "periférica" Florianópolis já teve sua primeira sessão deste tipo no ano de 1900, segundo Vellozo (2018).

${ }^{v} \mathrm{~s} / \mathrm{d}=$ sem dados.

vi Segundo Ramos (2018), foi fundado um segundo cinema chamado "Ideal", sem relação com o de 1913.

vii O conceito de integração social ou integração de classe se diferencia das breves discussões que serão levantadas mais à frente acerca da ideia de integração espacial abrangida por Lacerda (2012). Ela propõe tal categoria em oposição as ideias de segregação ou fragmentação para a análise do espaço urbano. Isso fará parte do debate da próxima sessão.

viii O "somente" diz respeito ao fato de que o primeiro filme sonoro em contexto mundial estreou em 1927: The Jazz Singer, dirigido por Alan Crosland. O gap temporal entre surgimento da tecnologia e a primeira exibição em Florianópolis foi quase o mesmo do período dos cinematógrafos itinerantes, como apresentado anteriormente.

ix O Hollywood's Golden Age, movimento cinematográfico centralizado nos Estados Unidos, ocorreu entre os anos 1920 e início dos 1960. Foi extremamente responsável pela expansão da cultura estadunidense pelo globo e também ditou linguagens cinematográficas que reverberam até hoje em filmmakers de todo o mundo (Whiteley, 2018; Kemp, 2011;)

x Darci Costa e Gilberto Gerlach, por exemplo, estão dentre os grandes expoentes na manutenção da arte cinematográfica alternativa em Florianópolis, especialmente por via dos Cineclubes (Ramos, 2018). Iniciativas por parte deles, assim como por instituições como o CIC e a Fundação BADESC são significativos na região e também descritos por Vellozzo (2018) e Maria (2008).

xi Biskind (2009) faz detalhada descrição do período, demonstrando como os estúdios responsáveis pela Era de Ouro (ver nota 8) entraram em decadência ao final dos anos 1960 e acabaram aumentando a liberdade criativa de diversos diretores e roteiristas oriundos da contracultura em voga nos EUA do período. Segundo o autor, tal fase se inicia com Bonnie and Clyde (Arthur Penn - 1967) e termina em 1980, com o lançamento do filme Raging Bull, de Martin Scorsese, finalizando esta "era". 
xii Distante aproximadamente $11 \mathrm{~km}$ do centro de Florianópolis, hoje este empreendimento está inserido em densa urbanização, às margens da BR-101, entre os bairros de Barreiros e Campinas. No entanto, a mais de 35 anos, foi um turning point em termos de "fonte de entretenimento" longe do centro da capital.

xiii Originalmente fundado como um cinema-mudo, teve no período anterior também os nomes de Art-

Nouveaux e Variedades.

xiv Surgiu como Centro Popular, também mudo, e foi a primeira localização do cinema Odeon, que depois migrou para o TAC.

${ }^{x v}$ Apesar de não se localizar no centro (bairro Estreito), o encerramento desta sala de cinema também é representativo para a análise.

xvi Apesar da grande importância para os estudos urbanos e do direito à cidade em sua carreira, Harvey tem, nos últimos anos, se dedicado especialmente em estudos econômicos e da teoria marxista em si.

xvii A crise financeira dos subprime de 2008 e os primeiros passos da "quarta revolução industrial" são só alguns exemplos disso.

xviii A questão da magnitude demográfica também deve ser levada em conta. Segundo dados do IBGE (2019), a atual estimativa de população de somente o município de São Paulo é superior a 12 milhões de habitantes, pouco menos que o dobro de todo o estado de Santa Catarina. A região conurbada de Florianópolis, por sua vez, tem uma população estimada de aproximadamente 970 mil habitantes (soma da população total dos quatro municípios).

xix Cabe ressaltar que o autor concorda, em boa parte, com esta abordagem, que deve ser vista em detalhe no trabalho original. Como forma de comparação, poder-se-ia dizer que shoppings centers e enclaves fortificados também apresentam seus graus de integração, maiores ou menores, com determinadas porções do espaço, o que se aplica também ao caso de Florianópolis e entorno.

${ }^{\mathrm{xx}} \mathrm{O}$ caso de Florianópolis é emblemático e foi fonte de diversos estudos, especialmente em relação ao seu último Plano Diretor Participativo. Para uma abordagem com enfoque nas condições para participação e que inclui casos de outras cidades catarinenses, ver Pereira (2015). Para uma publicação mais aprofundada especialmente sobre o PDP de Florianópolis, ver Peres et al (2013). 